\title{
Regulation of Enzymes of Lysine Biosynthesis in Corynebacterium glutamicum
}

\author{
By JOSEF CREMER, C. TREPTOW, L. EGGELING* AND H. SAHM \\ Institut für Biotechnologie der Kernforschungsanlage Jülich GmbH, PF 1913, D-5170, FRG
}

(Received 27 April 1988; revised 25 July 1988)

\begin{abstract}
The regulation of the six enzymes responsible for the conversion of aspartate to lysine, together with homoserine dehydrogenase, was studied in Corynebacterium glutamicum. In addition to aspartate kinase activity, the synthesis of diaminopimelate decarboxylase was also found to be regulated. The specific activity of this enzyme was reduced to one-third in extracts of cells grown in the presence of lysine. Aspartate-semialdehyde dehydrogenase, dihydrodipicolinate synthase, dihydrodipicolinate reductase, and diaminopimelate dehydrogenase were neither influenced in their specific activity, nor inhibited, by any of the aspartate family of amino acids. Homoserine dehydrogenase was repressed by methionine (to $15 \%$ of its original activity) and inhibited by threonine (4\% remaining activity). Inclusion of leucine in the growth medium resulted in a twofold increase of homoserine dehydrogenase specific activity. The flow of aspartate semialdehyde to either lysine or homoserine was influenced by the activity of homoserine dehydrogenase or dihydrodipicolinate synthase. Thus, the twofold increase in homoserine dehydrogenase activity resulted in a decrease in lysine formation accompanied by the formation of isoleucine. In contrast, repression of homoserine dehydrogenase resulted in increased lysine formation. A similar increase of the flow of aspartate semialdehyde to lysine was found in strains with increased dihydrodipicolinate synthase activity, constructed by introducing the dap $A$ gene of Escherichia coli (coding for the synthase) into C. glutamicum.
\end{abstract}

\section{INTRODUCTION}

L-Lysine is economically one of the most important amino acids. Commercially, the largest amounts are produced by Corynebacterium glutamicum, Brevibacterium flavum and Brevibacterium lactofermentum (Kleemann et al., 1985); therefore several studies have been done on the regulation of individual enzymes of lysine biosynthesis in these organisms with the aim of improving their productivity.

The entry of aspartate into lysine synthesis is controlled at the level of aspartate kinase activity (see Fig. 1). In contrast to Escherichia coli, only one aspartate kinase is present in $B$. flavum (Shiio et al., 1970). This enzyme is feedback-inhibited when both lysine and threonine are present in excess (Shiio \& Miyajima, 1969; Tosaka \& Takinami, 1978; Nakayama et al., 1966). If the enzyme is released from feedback inhibition, mutants excrete lysine in the range of 5-10 $\mathrm{g}^{-1}$ (Sano \& Shiio, 1970; Tosaka et al., 1978 a). Other amino acids of the aspartate family are not excreted in these mutants, indicating the presence of further control elements at branching points. Thus, homoserine dehydrogenase in B. flavum (Miyæjima \& Shiio, 1971; Miyajima et al., 1968) and B. lactofermentum (Tosaka et al., 1979) is repressed by methionine and inhibited by threonine. Mutants with decreased homoserine dehydrogeriase activity produce more lysine (Shiio \& Sano, 1969).

Interestingly, a further control at this branching point has been reported to be the synthesis of dihydrodipicolinate synthase. Tosaka et al. $(1978 b)$ reported that in $B$. lactofermentum upon leucine limitation a tenfold derepression of the enzyme specific activity occurs. This latter 


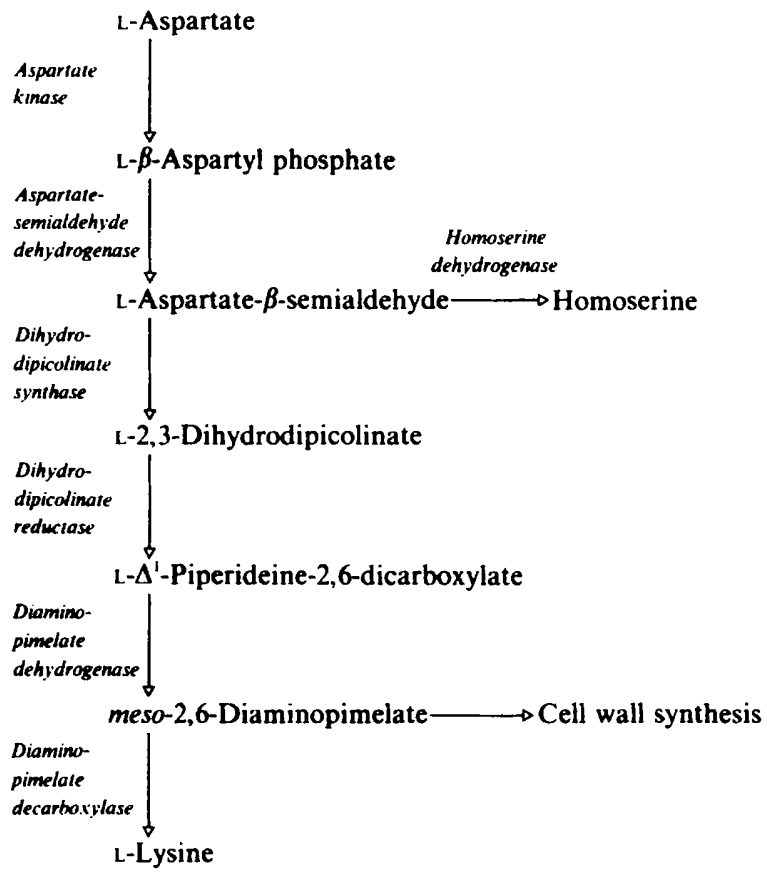

Fig. 1. Synthesis of lysine via the diaminopimelate dehydrogenase reaction.

observation coincides well with the fact that certain leucine-negative strains obtained by $\mathrm{N}$ methyl- $N^{\prime}$-nitro- $N$-nitrosoguanidine mutagenesis show increased lysine productivity (Tosaka $e t$ $a l ., 1978 b$ ). In spite of the economic interest, there have been no reports on the regulation of diaminopimelate decarboxylase, located at a further branching point, or that of aspartate semialdehyde dehydrogenase, dihydrodipicolinate reductase or diaminopimelate dehydrogenase. We therefore studied the regulation of these enzymes and re-examined that of other enzymes responsible for the conversion of aspartate to lysine. We included homoserine dehydrogenase and did experiments to elucidate the 'leucine effect' on lysine formation.

\section{METHODS}

Organisms and growth. The organisms used were Corynebacterium glutamicum ATCC 13032, the Leu- strain ATCC 14310, Brevibacterium lactofermentum ATCC 13869, and two independently isolated mutants of Corynebacterium glutamicum ATCC 13032 with deregulated aspartate kinase (strains DG52-5 and MH20). These were obtained by treatment with $N$-methyl- $N^{\prime}$-nitro- $N$-nitrosoguanidine $\left(250 \mu \mathrm{g} \mathrm{ml}{ }^{-1}, 30 \mathrm{~min}\right)$ and selected on plates containing the lysine analogue $S$-(2-aminoethyl)-L-cysteine plus L-threonine ( $12 \mathrm{mM}$ each). The medium for the plates was C.g. VIII, plus $2 \%(w / v)$ agar agar and $5 \%(w / v)$ urea, but with $\mathrm{CaCO}_{3}$ omitted. C.g. VIII contained, per litre: $20 \mathrm{~g}\left(\mathrm{NH}_{4}\right)_{2} \mathrm{SO}_{4}, 0.5 \mathrm{~g} \mathrm{KH}_{2} \mathrm{PO}_{4}, 0.5 \mathrm{~g} \mathrm{~K}_{2} \mathrm{HPO}_{4}, 0.25 \mathrm{~g} \mathrm{MgSO}_{4} .7 \mathrm{H}_{2} \mathrm{O}, 10 \mathrm{mg} \mathrm{MnSO} 4 . \mathrm{H}_{2} \mathrm{O}$, $10 \mathrm{mg} \mathrm{FeSO}{ }_{4} .7 \mathrm{H}_{2} \mathrm{O}, 1 \mathrm{mg} \mathrm{ZnSO} 4.7 \mathrm{H}_{2} \mathrm{O}, 0.2 \mathrm{mg} \mathrm{CuSO}_{4}, 0.2 \mathrm{mg}$ biotin. After sterilization, $4 \%(w / v)$ glucose and $2 \%(\mathrm{w} / \mathrm{v}) \mathrm{CaCO}_{3}$ were added.

For preparation of cell extracts and for measurement of amino acid production, a preculture was grown overnight at $30^{\circ} \mathrm{C}$ in complex medium (C.g. III) consisting of, per litre: $2.5 \mathrm{~g} \mathrm{NaCl}, 10 \mathrm{~g}$ yeast extract, $10 \mathrm{~g}$ peptone and $20 \mathrm{~g}$ glucose. Cells from this culture were washed once with $0.9 \% \mathrm{NaCl}$ and transferred to medium C.g. VIII to give an initial $\mathrm{OD}_{600}$ of about 0.7 (corresponding to $2 \times 10^{8} \mathrm{cells}^{-1}$ ). All cultivations were done in $100 \mathrm{ml}$ medium at $30^{\circ} \mathrm{C}$ on a rotary shaker at 100 r.p.m.

Preparation of extracts and enzyme assays. The cells were harvested by centrifugation and, after washing with 50 mu-potassium phosphate buffer pH 7.5, were suspended in the same buffer. Sonic extracts were prepared by disrupting the cells with a microtip-equipped Branson Sonifier at maximal settings $\left(5 \mathrm{~min}, 0^{\circ} \mathrm{C}\right)$. The resulting homogenate was centrifuged for $30 \mathrm{~min}$ at $10000 \mathrm{~g}$, and the supernatant used as cell-free extract. 


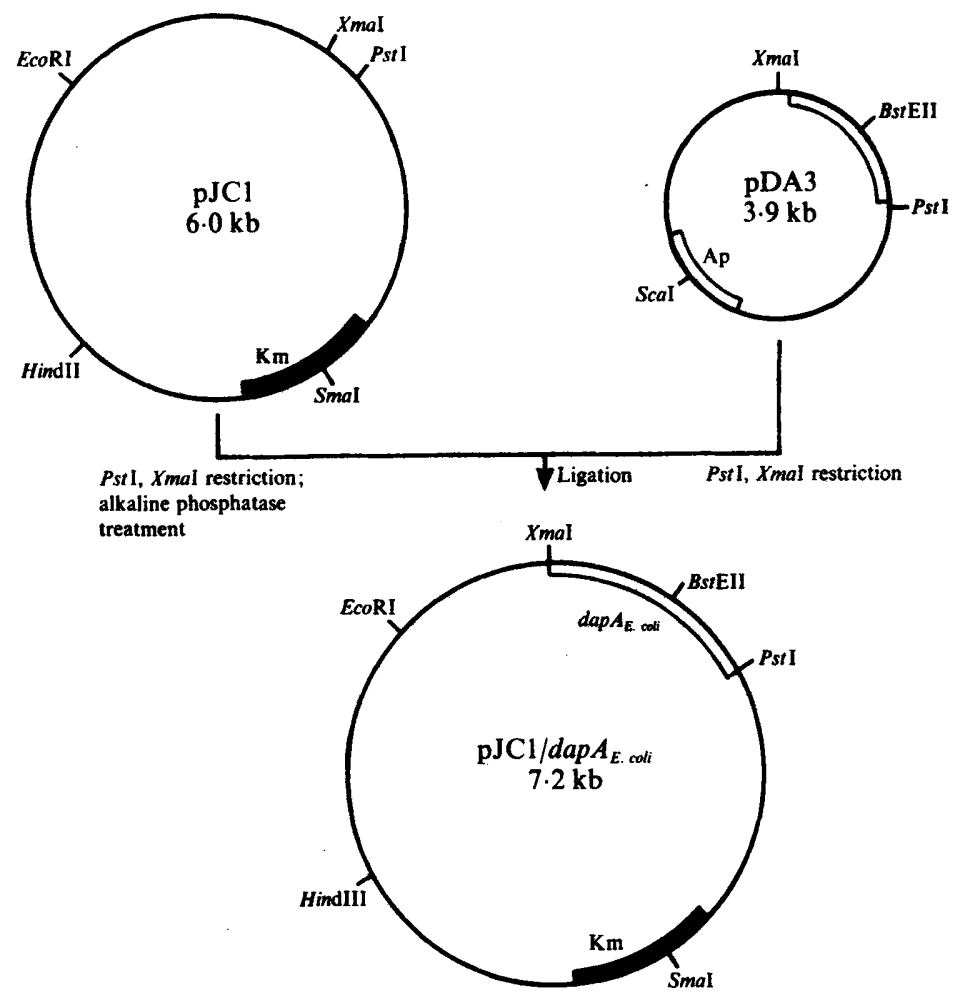

Fig. 2. Construction scheme of plasmid pJC1/dapA.

Aspartate kinase (EC 2.7.2.4) was assayed in extracts of cells suspended in $50 \mathrm{~mm}-\left(\mathrm{NH}_{4}\right)_{2} \mathrm{SO}_{4}, 100 \mathrm{~mm}$ Tris/ $\mathrm{HCl}$ pH 7.5 according to the method of Black \& Wright (1955). The assay mixture consisted of 100 mM-Tris/HCl pH 7.5, 13.3 mM-ATP, $24 \mathrm{~mm}-\mathrm{MgCl}_{2}, 468 \mathrm{~mm}-\left(\mathrm{NH}_{4}\right)_{2} \mathrm{SO}_{4}, 613 \mathrm{~mm}-\left(\mathrm{NH}_{3} \mathrm{OH}\right) \mathrm{Cl}, 93 \mathrm{~mm}$-potassium $L$-aspartate, and extract. The assay was incubated at $30^{\circ} \mathrm{C}$ for $30 \mathrm{~min}$ and the reaction stopped by the addition of $1 \mathrm{ml} 10 \%(\mathrm{w} / \mathrm{v}) \mathrm{FeCl}_{3} .6 \mathrm{H}_{2} \mathrm{O}, 3.3 \%(\mathrm{w} / \mathrm{v})$ trichloroacetic acid in $0.7 \mathrm{M}-\mathrm{HCl}$ to $1.5 \mathrm{ml}$ assay mixture. After centrifugation, the absorbance at $546 \mathrm{~nm}$ was measured and compared with standards obtained with aspartyl hydroxamate.

Aspartate-semialdehyde dehydrogenase (EC 1.2.1.11) was assayed in extracts of cells suspended in buffer containing $33 \%$ (v/v) glycerol and was assayed according to Hegemann et al. (1970) in the reverse of the biosynthetic reaction. The assay mixture consisted of $60 \mathrm{~mm}$-diethanolamine. $\mathrm{HCl}$ pH 9, 0.8 mM-NADP, $40 \mathrm{mM}-$ $\mathrm{Na}_{2} \mathrm{HAsO}_{4}, 0.12 \mathrm{M}-\mathrm{NaCl}, 1.5 \mathrm{mM}$-L-aspartate semialdehyde, and extract. The reaction was followed at $25^{\circ} \mathrm{C}$ and $340 \mathrm{~nm}$.

Dihydrodipicolinate synthase (EC 4.2.1.52) was assayed by the method of Yamakura et al. (1974). The assay mixture consisted of $0.2 \mathrm{M}$-Tris/ $\mathrm{HCl}$ pH $8,2 \mathrm{mM}$-L-aspartate semialdehyde, $4 \mathrm{~mm}$-sodium pyruvate, and extract. After incubation for $10 \mathrm{~min}$ at $30^{\circ} \mathrm{C}$, the $500 \mu \mathrm{l}$ assay mixture was mixed with $450 \mu \mathrm{l} 1 \mathrm{M}-\mathrm{HCl}$ and $50 \mu \mathrm{l}$ $o$-aminobenzaldehyde ( $20 \mathrm{mg}$ per $\mathrm{ml}$ ethanol). After $50 \mathrm{~min}$ incubation in the dark, the samples were centrifuged and their absorbance at $540 \mathrm{~nm}$ determined $\left(\varepsilon=1220 \mathrm{M}^{-1} \mathrm{~cm}^{-1}\right)$.

For determination of dihydrodipicolinate reductase (EC 1.3.1.26) the dapA gene of Escherichia coli, coding for dihydrodipicolinate synthase (Richaud et al., 1986), was transferred via plasmid pJCl (see below) into the dapB(reductase-) negative E. coli strain AT999 (Bukhari \& Taylor, 1971). Extracts of this strain with a dihydrodipicolinate synthase specific activity of $3.3 \mu \mathrm{mol} \mathrm{min} \mathrm{m}^{-1}$ (mg protein) ${ }^{-1}$ were used to synthesize the reductase substrate in $900 \mu \mathrm{l}$ of the following reaction mixture: $111 \mathrm{~mm}$-Tris/ $\mathrm{HCl} \mathrm{pH} 7.5,5 \mathrm{~mm}$-aspartate semialdehyde, 1.1 mM-NADPH, 6 mM-sodium pyruvate, and $50 \mu l$ extract of AT999 (pJC1/dapA) (=1 U dihydrodipicolinate synthase). This assay was incubated for $10 \mathrm{~min}$ at $30^{\circ} \mathrm{C}$ and the reductase reaction started by the addition of extract previously incubated for $3 \mathrm{~min}$ at $70^{\circ} \mathrm{C}$ (the heat treatment of the extract was necessary to inactivate the homoserine dehydrogenase and NADPH oxidase activities). The NADPH-dependent reduction was followed at $340 \mathrm{~nm}$ and $30^{\circ} \mathrm{C}$. 
meso-Diaminopimelate dehydrogenase (EC 1.4.1.16) was assayed in the reverse direction at $30^{\circ} \mathrm{C}$ in the following assay mixture: $200 \mathrm{~mm}$-glycine/ $\mathrm{NaOH}$ pH 10.5, 2 mM-NADP, 4 mM-meso-diaminopimelate.

Diaminopimelate decarboxylase (EC 4.1.1.20) was assayed in a system containing 50 mM-potassium phosphate pH 7.5, 0.1 mM-pyridoxal phosphate, 0.5 mM-EDTA, $25 \mathrm{~mm}$-diaminopimelate, and extract. After incubation at $30^{\circ} \mathrm{C}$ for various times (at least four points), the lysine formed was determined by amino acid analysis (see below).

Homoserine dehydrogenase (EC 1.1.1.3) was assayed at $25^{\circ} \mathrm{C}$ in $66 \mathrm{mM}$-potassium phosphate $\mathrm{pH} 7 \cdot 0,0.2 \mathrm{~mm}$ NADPH, $0.1 \mathrm{~mm}$-aspartate semialdehyde. The activity was followed at $340 \mathrm{~nm}$ or determined by direct homoserine analysis (see below), giving comparable results.

All assays were checked for linearity with respect to time and protein concentration. They were optimized for the $\mathrm{pH}$ of the incubation buffer and for the concentrations of substrates and coenzymes. Determinations were done with at least three independently generated extracts. Specific activities are given in $\mu \mathrm{mol} \mathrm{min}^{-1}\left(\mathrm{mg}^{\circ}\right.$ protein) $)^{-1}$.

$D N A$ manipulation. The shuttle vector $\mathrm{pJCl}$ and the plasmid $\mathrm{pDA} 3$ containing the dapA gene of $E$. coli (Richaud et al., 1986) were isolated from $E$. coli DHS and RDA8, respectively, by the alkaline lysis method (Birnboim \& Doly, 1979). The construction scheme for the recombinant plasmid pJC1/dapA is shown in Fig. 2. The source of the DNA-modifying enzymes was Boehringer, whose recommendations for use were followed throughout. The ligation mix was used to transform $E$. coli DH5 (Hanahan, 1985) using the RbCl method, and $\mathrm{Kan}^{\mathrm{r}}$ transformants were selected. Four of the transformants assayed had a specific dihydrodipicolinate synthase activity of $0 \cdot 8-1 \cdot 1$ (host 0.04 ) and gave the restriction pattern of $\mathrm{pJCl} /$ dapA. This plasmid was isolated on a large scale by caesium chloride density gradient centrifugation (Maniatis et al., 1982) and used to transform spheroplasts of $C$. glutamicum (Thierbach et al., 1988).

Amino acid analysis. Amino acids were analysed as their $\sigma$-phthalaldehyde derivatives by reversed-phase chromatography. Derivatives were formed via automatic pre-column derivatization using the $o$-phthalaldehyde reagent (Pierce) with an LC 1090 HPLC (Hewlett-Packard). The separation was achieved on a Lichrospher RP-18 column (Merck) using a gradient consisting of $0.1 \mathrm{M}$-sodium acetate pH 7.2 and methanol. Detection was via UV absorbance at $340 \mathrm{~nm}$ or fluorescence at $450 \mathrm{~nm}$ with excitation at $230 \mathrm{~nm}$.

\section{RESULTS}

\section{Activities of the enzymes of lysine synthesis during growth in batch culture}

Washed cells of $C$. glutamicum were inoculated in parallel and one flask harvested at each time point to prepare the extract for enzyme determinations. As shown in Fig. 3, the specific activities of aspartate-semialdehyde dehydrogenase and dihydrodipicolinate synthase exhibited a more than threefold increase during the early exponential growth phase. By contrast, the other four enzyme activities determined varied only slightly with cultivation time.

\section{Repression and inhibition of the enzymes by amino acids}

The amino acids used were those of the aspartate family, and leucine. All amino acids were taken up from cultures, and consequently might influence the internal amino acid pool. This was not the case with diaminopimelic acid since all attempts to force the organism to use this compound as a nitrogen source failed. This explains why no mutants of $C$. glutamicum requiring diaminopimelic acid have been found (Follettie et al., 1986) and agrees with a similar situation in Bacillus sphaericus (White, 1983).

The only two enzymes found to be regulated in their synthesis were diaminopimelate decarboxylase and homoserine dehydrogenase (Table 1), both located at branching points. The decarboxylase was repressed by lysine to a degree similar to that found in $E$. coli (Stragier et al., 1983). Our results are thus at variance with the recent report by Yeh et al. (1988a), who found that the levels of dihydrodipicolinate synthase, diaminopimelate dehydrogenase and diaminopimelate decarboxylase in $C$. glutamicum were all independent of the addition of lysine to the growth medium. The repression of homoserine dehydrogenase by L-methionine has already been reported for Brevibacterium flavum (Miyajima \& Shiio, 1971). Surprisingly, the enzyme was derepressed about twofold by leucine; this is probably of relevance for the decrease in lysine formation obtained by added leucine in lysine-producing strains. No repression of dihydrodipicolinate synthase was found with any of the amino acids tested, though in $B$. lactofermentum an eightfold repression by leucine has been reported (Tosaka et al., 1978b). To enhance any possible effect of L-leucine on the synthesis of the enzyme, the Leu- mutant $C$. 


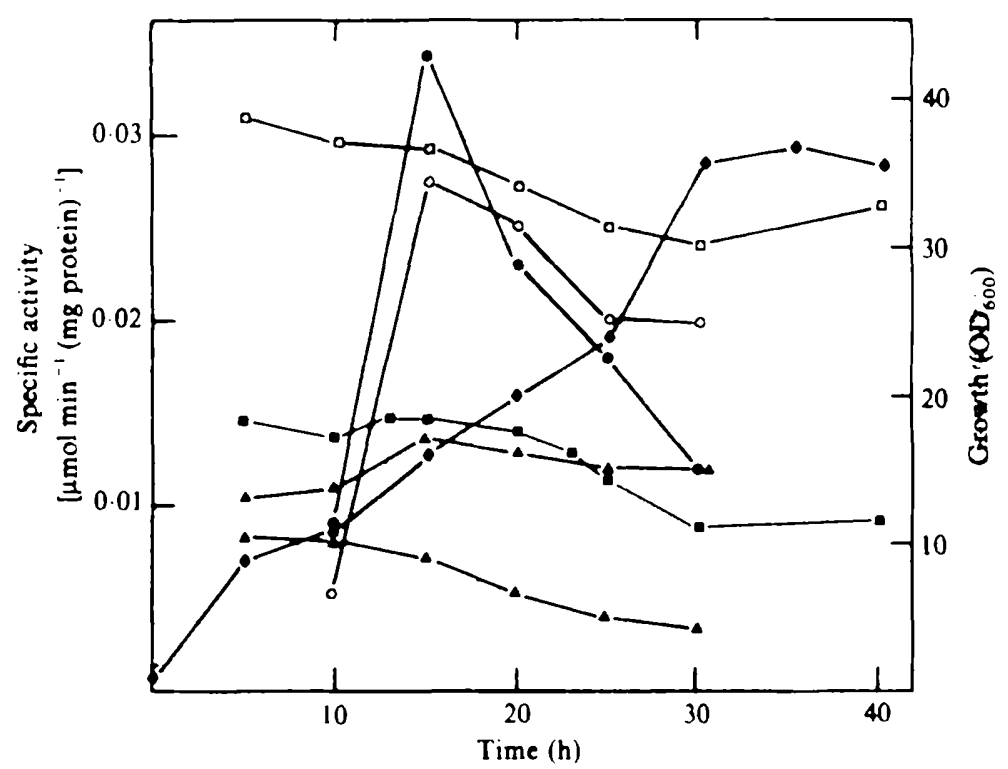

Fig. 3. Growth-dependent activities of enxymes of lysine synthesis in $C$. glutamicum. Growth; $\triangle$, aspartate kinase; $O$, aspartate-semialdehyde dehydrogenase; $O$, dihydrodipioolinate synthase (values divided by 10 before plotting); $\Delta$, dihydrodipicolinate reductase; $\boldsymbol{a}$, diaminopimelate dehydrogenase (values divided by 10 before plotting); $\square$, diaminopimelate decarboxylase.

glutamicum ATCC 14310 was used. This mutant was grown in the presence of 10 mm-L-leucine and the enzyme activity determined in one part of the cells. The other part was washed, transferred to leucine-free medium and incubated for $6 \mathrm{~h}$. The resulting enzyme specific activity was 0.24 as compared to 0.16 in the extract prepared at the beginning of the transfer and comparable to that in the wild-type. In a similar experiment with a Leu- mutant of $B$. lactofermentum a tenfold derepression of the enzyme activity has been reported (Tosaka et al., 1978 b). We determined a constant specific activity in B. lactofermentum ATCC 13869, whether or not $10 \mathrm{~mm}$-L-leucine was included in the growth medium.

The same amino acids which were tested for their influence on the synthesis of the lysinebiosynthetic enzymes were also tested for a possible influence on enzyme activity (Table 2). No regulation of dihydrodipicolinate synthase, dihydrodipicolinate reductase, diaminopimelate dehydrogenase or diaminopimelate decarboxylase was found. Aspartate kinase was inhibited by L-threonine plus L-lysine, confirming earlier reports for Micrococccus glutamicus (Nakayama et al., 1966). The activity of aspartate-semialdehyde dehydrogenase was inhibited by L-threonine and L-lysine, but since the enzyme was assayed in the reverse reaction at $\mathrm{pH} 10$, any apparent regulatory effect must be considered with caution. Homoserine dehydrogenase was inhibited almost completely by inclusion of L-threonine in the enzyme assay, whereas L-isoleucine inhibited the activity to about $50 \%$.

\section{Control of the flow of aspartate semialdehyde to either dihydrodipicolinate or homoserine}

Dihydrodipicolinate synthase and homoserine dehydrogenase, both competing for the aldehyde, have comparable specific activities. The apparent $K_{\mathrm{m}}$ of the dehydrogenase for the aldehyde is $0.7 \times 10^{-3} \mathrm{M}$, whereas that of the synthase is $6.2 \times 10^{-3} \mathrm{M}$. These values, determined from Lineweaver-Burk plots, are of the same order as those for the enzymes from $B$. lactofermentum (Tosaka et al., 1979). This kinetic analysis, together with the regulation of homoserine dehydrogenase, suggests that the partitioning of aspartate semialdehyde is primarily controlled at the level of homoserine dehydrogenase. 


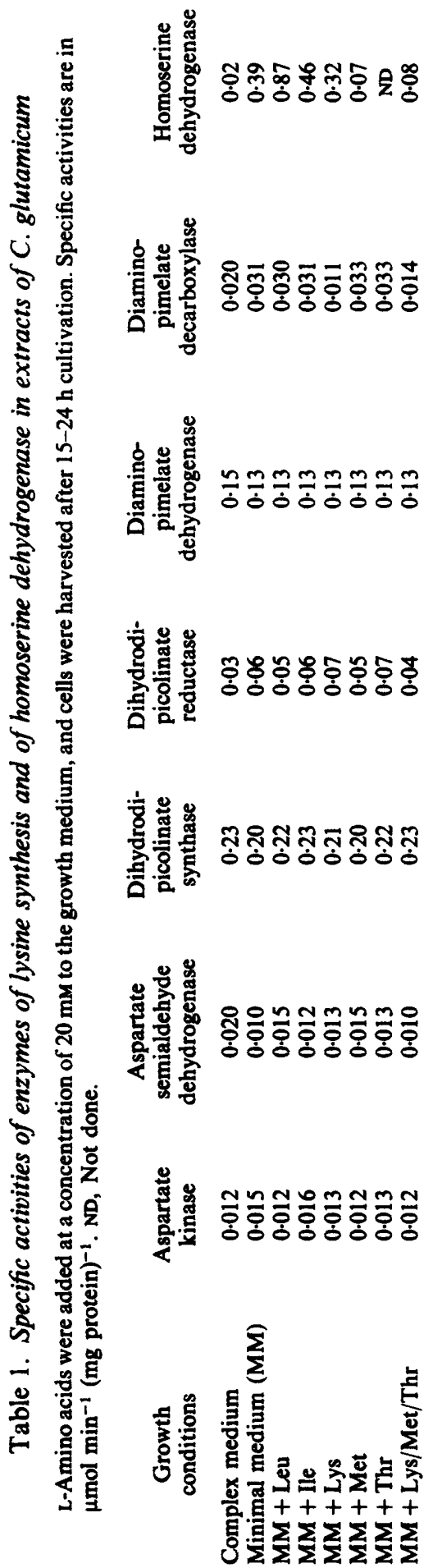


Table 2. Inhibition of enzymes in extracts of $C$. glutamicum by amino acids

Extracts were prepared from cells grown in minimal medium. L-Amino acids were added to a final

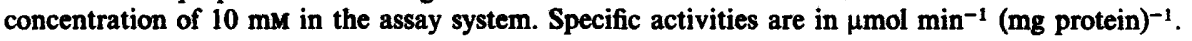

$\begin{array}{lccc}\text { Addition } & \begin{array}{c}\text { Aspartate } \\ \text { kinase }\end{array} & \begin{array}{c}\text { Aspartate-semialdehyde } \\ \text { dehydrogenase }\end{array} & \begin{array}{c}\text { Homoserine } \\ \text { dehydrogenase }\end{array} \\ \text { None } & 0.012 & 0.019 & 0.47 \\ \text { Leu } & 0.014 & 0.015 & 0.50 \\ \text { Lys } & 0.012 & 0.012 & 0.42 \\ \text { Met } & 0.014 & 0.015 & 0.44 \\ \text { Ile } & 0.015 & 0.016 & 0.21 \\ \text { Thr } & 0.010 & 0.010 & 0.02 \\ \text { Lys/Met/Thr } & 0.003 & 0.011 & 0.02\end{array}$

To verify this view, two independently isolated lysine-producing mutants of $C$. glutamicum ATCC 13032 were grown under conditions repressing homoserine dehydrogenase $(10 \mathrm{~mm}$ methionine) and the amounts of lysine formed were compared. In strain DG52-5 the concentration of lysine in the growth medium was increased from 40 to $50 \mathrm{mM}$, and in strain MH20 from 37 to $43 \mathrm{mM}$, respectively. A similar effect of methionine was found with a strain of B. flavum (Miyajima \& Shiio, 1971). By contrast, increased homoserine dehydrogenase activity was attained by cultivation of the strains with 10 mM-leucine. In both cases the increased dehydrogenase activity was comparable to that of the wild-type and the lysine yield was reduced: from 37 to $27 \mathrm{mM}$ with strain DG52-5, and from 36 to $30 \mathrm{mM}$ with strain MH20. Additionally, the cultures with derepressed homoserine dehydrogenase formed traces of isoleucine (1-2 mM). This is further evidence for the drain of the aldehyde into the threonine branch.

To ascertain whether the flow of aspartate semialdehyde can also be altered via an increase in dihydrodipicolinate synthase activity, the dap $A$ gene of $E$. coli (coding for the synthase) was used (Richaud et al., 1986). The construction of the $C$. glutamicum/E. coli vector containing dapA is outlined in Methods. The plasmid pJC1/dapA was then introduced in the lysine-producer $C$. glutamicum MH20 and transformants were assayed for dihydrodipicolinate synthase specific activity. This was $1 \cdot 6-2 \cdot 2$, as compared to $0 \cdot 2$ in the original strain. Since the synthase of $E$. coli is inhibited by lysine, the specific activity was determined with 50 mM-lysine in the assay system. Under these conditions the specific activity was 0.5 ; thus even under the unfavourable assumption of very high internal lysine concentrations the presence of the $E$. coli dapA gene could result in a 2.5 -fold activity increase in the transformants. The fermentation of two transformants yielded 41 and 42 mM-lysine, respectively, whereas controls (strains containing the vector without the $E$. coli dapA gene) yielded 33 and $34 \mathrm{mM}$.

\section{DISCUSSION}

The synthesis of lysine from aspartate in Corynebacterium glutamicum proceeds via the diaminopimelate dehydrogenase reaction (Misono et al., 1979). Possibly, an additional bypass via succinylated (or acetylated) intermediates might occur. The only evidence for this latter variant of lysine synthesis is one measurement of aminoketopimelate succinylase using a problematic assay (Tosaka \& Takinami, 1978), and comparisons of the distribution of ${ }^{13} \mathrm{C}$ in lysine synthesized from labelled glucose based on the assumption that both pathways might occur (Yamaguchi et al., 1986). A physiological need for the presence of both pathways occurring together is questionable. This is especially the case for coryneform bacteria, where there are usually simple types of regulation, which might be one reason for the successful use of these organisms for amino acid production (Kinoshita, 1985). It therefore appears that ignorance of the diaminopimelate dehydrogenase reaction in coryneform bacteria at the beginning of the research on lysine production resulted in the branched pathway currently presented. 
The targets for the regulation of the diaminopimelate dehydrogenase pathway in $C$. glutamicum are aspartate kinase and diaminopimelate decarboxylase. The recognized effectors are L-threonine and L-lysine. Much attention has already been paid to the regulation of aspartate kinase activity. The enzyme of $C$. glutamicum is inhibited to $30 \%$ of its activity by threonine plus lysine, a pair of amino acids which represent both the lysine/diaminopimelate and the methionine/threonine/isoleucine branches of the biosynthesis of the aspartate family of amino acids. This type of control is sufficient to regulate the synthesis of all amino acids, provided that the remaining aspartate kinase activity supplies sufficient precursor for methionine synthesis.

Diaminopimelate decarboxylase has not previously been recognized as a regulatory enzyme in coryneform bacteria. In Bacillus sphaericus (Bartlett \& White, 1986) no repression of the enzyme occurs, whereas in $E$. coli a complex type of regulation exists, involving the lys $R$ gene which modulates the expression of $l y s A$, coding for the decarboxylase (Stragier et al., 1983). This results in repression of synthesis of the enzyme by lysine, which can be overcome by the addition of diaminopimelate. The cloning of the diaminopimelate decarboxylase gene of $C$. glutamicum has recently been reported (Yeh et al., 1988b). Interestingly, a DNA sequence upstream of lys $A$ was found which was necessary for full expression of the decarboxylase on a cloned fragment. We propose that the upstream region is the target for the lysine-dependent regulation of lys $A$ integrated in the genome of $C$. glutamicum. Diaminopimelate is probably also involved in regulation, as is the case with lys $A$ of $E$. coli. Experiments to elucidate this are possible with cloned DNA fragments in a host where diaminopimelate can enter the cell. In any case, the decarboxylase is, in addition to the long-recognized aspartase kinase, a further candidate for direct manipulation to achieve increased lysine formation.

At the branching of the flow of aspartate semialdehyde to either homoserine or diaminopimelate, a regulation of dihydrodipicolinate synthase activity has not been observed in C. glutamicum. This is in contrast to E. coli (Patte, 1983) or Bacillus sphaericus (Bartlett \& White, 1986), where lysine inhibits the enzyme. In $C$. glutamicum the regulation of the flow of aspartate semialdehyde is only via homoserine dehydrogenase. The repression of this enzyme by methionine and its inhibition by threonine allow a balanced flow to the methionine/threonine/ isoleucine branch, whereas no fine-tuning of lysine synthesis between aspartate kinase and diaminopimelate decarboxylase occurs. The flow of aspartate semialdehyde to lysine can be increased either by enhancement of dihydrodipicolinate synthase activity or by a decrease in homoserine dehydrogenase activity. This is in agreement with the fact that the profitable use of several lysine-producing Brevibacterium flavum strains could be subsequently attributed to a decreased homoserine dehydrogenase activity (Shiio \& Sano, 1969). Such mutants are also advantageous for fermentations since no adjustment of the threonine and methionine supply is required as it is with mutants with no homoserine dehydrogenase activity.

The observed negative effect of leucine on lysine formation is most probably due to an increased drain-off of aspartate semialdehyde via increased homoserine dehydrogenase activity. If this is the only effect of leucine, this effect should not be found with homoserinedehydrogenase-negative mutants. To confirm this, precisely defined mutants, perhaps obtained by transposon mutagenesis, will have to be analysed.

The authors thank Dr C. Richaud for pDA3. They thank Dr Bachmann and Dr Buchholz for aspartate semialdehyde and Dr Aragon for strain DG52-5. This work is part of a common project with DEGUSSA AG and Lehrstuhl für Genetik, Universitāt Bielefeld, supported by grants from the BMFT (038409).

\section{REFERENCES}

BARTlett, A. T. M. \& White, P. J. (1986). Regulation of the enzymes of lysine biosynthesis in Bacillus sphaericus NCTC 9602 during vegetative growth. Journal of General Microbiology 132, 3169-3177.

BirNBom, H. C. \& DOLY, J. (1979). A rapid alkaline extraction procedure for screening recombinant plasmid DNA. Nucleic Acids Research 7, 1513-1523.
Black, S. \& Wright, N. G. (1955). Aspartic $\beta$ semialdehyde dehydrogenase and aspartic $\beta$-semialdehyde. Journal of Biological Chemistry 213, 39-50.

Burhari, A. I. \& TAYLOR, A. L. (1971). Genetic analysis of diaminopimelic acid and lysine-requiring mutants of Escherichia coli. Journal of Bacteriology 105, 844-854. 
Follettie, M. T., Yeh, P., Shink, H. K., Peoples, O. P., HAN, K. S. \& SinSKeY, A. J. (1986). Development of recombinant DNA technology for Corynebacterium glutamicum: isolation and characterization of amino acid biosynthetic genes. Fifth International Symposium on the Genetics of Industrial Microorganisms, Split, Jugoslavia, p. 128 (abstract).

HaNAHAN, D. (1985). Techniques for transformation of Escherichia coli. In DNA Cloning, vol. 1, pp. 109-136. Edited by D. M. Glover. Oxford \& Washington: IRL Press.

Hegemann, G. D., Cohen, G. N. \& Morgan, R. (1970). Aspartic semialdehyde dehydrogenase. Methods in Enzymology, 17A, 708-713.

KnNoshrta, S. (1985). Glutamic acid bacteria. In Biology of Industrial Microorganisms, pp. 116-142. Weinheim: Verlag Chemie.

KLeemanN, A., Leuchtenberger, W., Hoppe, B. \& TANNER, H. (1985). Amino acids. In Ullmann's Encyclopedia of Industrial Chemistry, vol. A2, pp. 57-97. Weinheim: VCH-Verlagsgesellschaft.

Maniatis, T., Fritsch, E. F. \& SAMBroOK, J. (1982). Molecular Cloning: a Laboratory Manual. Cold Spring Harbor, NY: Cold Spring Harbor Laboratory.

Misono, H., Togawa, H., Yamamoto, T. \& Soda, $K$. (1979). meso-2,6-Diaminopimelate D-dehydrogenase : distribution and the reaction product. Journal of Bacteriology 137, 22-27.

MIYAMMA, R. \& SHIo, I. (1971). Regulation of aspartate family amino acid biosynthesis in Brevibacterium flavum. IV. Repression of the enzymes in threonine biosynthesis. Agricultural and Biological Chemistry 35, 424-430.

Miyatima, R., Otsuka, S. I. \& Shio, I. (1968). Regulation of aspartate family amino acid biosynthesis in Brevibacterium flavum. I. Inhibition by amino acids of the enzymes in threonine biosynthesis. Journal of Biochemistry 63, 139-148.

Nakayama, K., Tanaka, H., Hagino, H. \& KINOSHITA, S. (1966). Studies on lysine fermentation. V. Concerted feedback inhibition of aspartokinase and the absence of lysine inhibition on aspartic semialdehyde-pyruvate condensation in Micrococcus glutamicus. Agricultural and Biological Chemistry 30, 611-616.

PATTE, J.-C. (1983). Diaminopimelate and lysine. In Amino Acids, Biosynthesis and Genetic Regulation, pp. 213-228. Edited by K. M. Hermann \& R. L. Somerville. London \& Amsterdam: AddisonWesley.

Richaud, F., Richaud, C., Ratet, P. \& Patte, J.-C. (1986). Chromosomal location and nucleotide sequence of the Escherichia coli dapA gene. Journal of Bacteriology 166, 297-300.

SANO, K. \& SHIO, I. (1970). Microbial production of Llysine. III. Production by mutants resistant to $S$-(2aminoethyl)-L-cysteine. Journal of General and Applied Microbiology 16, 373-391.

ShIo, I. \& MryaJma, R. (1969). Concerted inhibition and its reversal by end products of aspartate kinase in Brevibacterium flavum. Journal of Biochemistry 65, 849-859.

SHIIO, I. \& SANO, K. (1969). Microbial production of Llysine. II. Production by mutants sensitive to threonine or methionine. Journal of General and Applied Microbiology 15, 267-287.

ShiIO, I., MrYamma, R. \& SANo, K. (1970). Genetically desensitized aspartate kinase to the concerted feedback inhibition in Brevibacterium flavum. Journal of Biochemistry 68, 701-710.

Stragier, P., Richaud, F., BORNe, F. \& PATte, J.-C. (1983). Regulation of diaminopimelate decarboxylase synthesis in Escherichia coli. I. Identification of a lys $R$ gene encoding an activator of the lys $A$ gene. Journal of Molecular Biology 168, 307-320.

Thierbach, G., Schwarzer, A. \& PÜHLER, A. (1988). Transformation of spheroplasts and protoplasts in Corynebacterium glutamicum. European Journal of Applied Microbiology and Biotechnology (in the Press).

Tosaka, O. \& Takinami, K. (1978). Pathway and regulation of lysine biosynthesis in Brevibacterium lactofermentum. Agricultural and Biological Chemistry 42, 95-100.

Tosaka, O., Takinami, K. \& Hirose, Y. (1978a). LLysine production by $S$-(2-aminoethyl)-L-cysteine and $\alpha$-amino- $\beta$-hydroxyvaleric acid resistant mutants of Brevibacterium lactofermentum. Agricultural and Biological Chemistry 42, 745-752.

Tosaka, O., Hirakawa, H., TAkINAM, K. \& Hirose, Y. (1978b). Regulation of lysine biosynthesis by leucine in Brevibacterium lactofermentum. Agricultural and Biological Chemistry 42, 1501-1506.

Tosaka, O., IshiHARA, M., Mornnaga, Y. \& TAKINAMI, K. (1979). Mode of conversion of asparto $\beta$ semialdehyde to L-threonine and L-lysine in Brevibacterium lactofermentum. Agricultural and Biological Chemistry 43, 265-270.

WHITE, P. J. (1983). The essential role of diaminopimelate dehydrogenase in the biosynthesis of lysine by Bacillus sphaericus. Joumal of General Microbiology 129, 739-749.

Yeh, P., Sicard, A. M. \& SingKey, A. J. (1988a). General organization of the genes specifically involved in the diaminopimelate-lysine biosynthetic pathway of Corynebacterium glutamicum. Molecular and General Genetics 212, 105-111.

Yeh, P., Sicard, A. M. \& SinsKey, A. J. (1988b). Nucleotide sequence of the lys $A$ gene of Corynebacterium glutamicum and possible mechanisms for modulation of its expression. Molecular and General Genetics 212, 112-119.

Yamaguchi, K., Ishino, S., Araki, K. \& ShIrahata, K. (1986). ${ }^{13} \mathrm{C}$ NMR studies of lysine fermentation with a Corynebacterium glutamicum mutant. Agricultural and Biological Chemistry 50, 2453-2459.

YamakURa, F., Ikeda, Y., Kmura, K. \& Sasarawa, T. (1974). Partial purification and some properties of pyruvate-aspartic semialdehyde condensing enzyme from sporulating Bacillus subtilis. Journal of Biochemistry 76, 611-621. 